\title{
Design of Rare Disease Based Knowledge Model Net (RDKMN) in Schools Attended by Affected Students, as an Inclusive and Didactic Tool
}

\author{
Maider Pérez de Villarreal \\ Department of Psychology and Teaching, Campus Arrosadía S/N., Public University of Navarra, Spain
}

Copyright $(\mathrm{C} 2018$ by authors, all rights reserved. Authors agree that this article remains permanently open access under the terms of the Creative Commons Attribution License 4.0 International License

\begin{abstract}
Rare diseases (RD) are those affecting at least 1 of 2.000 inhabitants. Many RD, induce disabling conditions and those school age affected children usually miss classes due to the complicated diagnostic procedures and the several medical treatments they need, thereafter. It is still unknown the exact number of students in this situation in Navarra (Spain), although according to data from the INE [16], there should be at least 1300 children with disabilities from which at least 372 children in school age could be RD affected. These students should be able to be identified in schools, as the vast majorities need help at some point, derived in some cases from cognitive deficiencies but in others, from their absence of classes due to health complications. Some Rare Disease Affected Students (RDAS) also suffer from bullying due to the ignorance of their peers or even teachers, towards their situation. In this paper, the use of Cmap Tools software, together with a planned intervention in each school from Navarre, attended by at least, one RDAS, is proposed for creating knowledge models based on the specific RD affecting children in Navarre. This way, a RD based Knowledge Model Net (RDKMN) could be built, together with affected and non affected students, and this meaningful knowledge could be useful for any school attended by children suffering the same disease in Spain or other European countries. This could become a powerful international inclusive and didactic tool, which could help normalizing RD and including RDAS in the educational field, creating inclusive schools, and therefore spreading the knowledge to the social field.
\end{abstract}

Keywords Knowledge Model Net (KMN), Rare Disease Affected Students (RDAS), Meaningful Learning, Inclusive and Didactic Tool

\section{Introduction}

The education of the XXI century needs to face a number of challenges, some of which come from the so-called society of knowledge and information. These can be summarized in a change of an ethic of obligation for another of responsibility, widespread use of information and communication technologies, the so called ICT (Information and Communications Technology), and the requirement of a school, in generic terms, of quality, accountable to society and which includes every student, encouraging them to get universal literacy, motivation to learn and discipline for long life learning. It is in this new context in which the teacher's classical role has to change [17]. It is a new concept which is on the basis of education where the teaching dimension is subordinated to what it is learnt and how students will learn better and will get what they have set as a target. That is to say, education is based in learning and student-centered and what society needs is a conceptual change [24], as it will create the first generations of "Knowledge workers". Primary and Secondary Schools as well as Universities have to use their potential in order to promote teaching/learning quality, define adequate learning results and point the way to get them. They are institutions that have to include all members of society and provide the tools to perform best practices, assume compromises in order to provide society and especially handicapped members a better service [27]. This educational context faces a cognitive-constructivist model, ideal breeding ground for stimulating meaningful learning, avoiding conceptual mistakes and allowing students to build and master knowledge in order to be creative and critical citizens [17]. In this paradigm, students can play an active role not only learning about the final product, but through the process itself (metacognition). The teacher's responsibility is primarily to create conditions that facilitate the transformation of information in useful, substantive knowledge, which is incorporated and well-articulated in the students' knowledge in their long-term memory. This educational frame should be appropriate for all kind of students, giving place to the attention to diversity and especially including 
Rare Disease Affected Students (RDAS) who face difficult situations not only in the health field but also in other life areas, such as education and the social ambit.

Rare Diseases (RD) are diseases with a particularly low prevalence; they are considered those affecting at least 5 of 10,000 inhabitants (or 1 in 2000 inhabitants), criteria followed by most European countries. According to EUCERD (European Union Community of Experts on Rare Diseases)[10] the total number of people affected by RDs in the EU is estimated at between 27 and 36 million. Most $\mathrm{RD}$ are genetic diseases, the others being rare cancers, auto-immune diseases, congenital malformations, toxic and infectious diseases among other categories [12], which endure severe disabling conditions, which make difficult attending classes regularly. Many RD, are chronic, degenerative and disabling and due to the complicated diagnostic and the essential medical care, most affected children in school age, must miss classes, implying difficulties to reach to their peers' level, not always due to cognitive deficiencies, but to school absence. It is noteworthy the average time to obtain the diagnosis is around 10 years and anyone can suffer a rare pathology at any stage of life.

Yet it is unknown the exact number of patients in school age in this situation in Navarre (Spain). According to the INE (Statistics Institute of Navarre) [16], there are approximately 1900 "0-16 year old children" with disabilities, some of whom might be RDAS. However, more accurate data needs to be provided, since it is estimated that 1 in 2000 inhabitants might be Rd affected, this means that if the total population of Navarre in 2017 is 643234 inhabitants, there should be around 322 people RD affected, and if the percentage of children population in the demographic pyramid of Navarre is around $15,76 \%$, there might be at least, around 51 children in the stage of primary and secondary education who might be RD affected. This data shows the amount of RDAS in primary and secondary education in Navarre may be large enough for caring about it, and enough to meet their special educational needs without big expenses.

\subsection{GERNA}

GERNA [11], is an association which meets people and families from Navarre affected by some of the rare or infrequent diseases already diagnosed or in the way to be diagnosed. It emerged from the need to gather the entire group of families and people with $\mathrm{RD}$, making their common needs visible and proposing solutions to improve their wellbeing and quality of life. The Educational sector of GERNA met with teachers from the Public University of Navarra, with the aim of standardizing a protocol to carry out educational interventions in schools to make visible RDAS, show their reality to their peers and promote awareness, as a previous step to avoid bullying, since it has been reported [3] the vast majority of RDAS suffer or have suffered bullying at school, especially in the cases in which the image of the child is compromised. The social awareness and normalization of RDAS is as important as the provision of educational methodologies that facilitate their curricular adaptation.

\subsection{Theoretical Framework of Ausubel, Novak and Gowin}

This is the reason why we provide a well-known theoretical framework, tested with great results in the United States, developed by experts in education, such as Ausubel, Novak and Gowin,. This frame is suited as well as its methodological application through the construction of concept maps $(\mathrm{CM})$ and the diagram "V" of Gowin, to undertake educational changes. In general, concept maps (CM) are diagrams indicating relationships between key concepts or words we use to represent concepts and it is a technique proposed and developed by Joseph Novak [20]. Concept maps are powerful tools for describing structures of disciplinary knowledge through conceptual hierarchies or meanings, from general to more specific rules clearly and without forgetting the interpretation and explanation of who produces and prepares sense. Graphic icons linked to concepts of the CM can be displayed by clicking on them, and then, on the writing that appears. Information shall be so displayed. The original map with the associated resources is available via the free download software Cmap Tools, of the Institute for Human and Machine Cognition $[6,19]$. Several research studies $[20,13,3]$ show wide evidence demonstrating the great potential of $\mathrm{CM}$ to improve teaching, both for the diagnosis of students' prior knowledge and for the design and implementation of consistent curriculum and transparent instruction by the teacher.

\subsection{Heuristic Tools and Inclusive School}

These children are also members of our society and will be part of our future. Therefore, we should provide them the tools to be included in an inclusive and egalitarian society, which is a reflection of the knowledge and values acquired at school. In spite of the lifelong impact which many RDs entail and the beyond question complexity involved in many of these diseases, we have the moral duty of improving their education, considering their right to be educated and take part of a changing society as human beings and develop themselves according to their possibilities, since there are some less serious conditions which are compatible with a better quality of life during childhood and youth. During this period and in cases in which students may attend classes (in person or virtually), we suggest the possibility of using ICT, such as the free software Cmap Tools (IHMC, Florida, USA). By using this tool we can facilitate their learning by creating Knowledge Models (KM), which may help them be more creative and 
feel more valuable for society, therefore increasing their self-esteem. Knowledge modelling is proposed as a methodology to be used in primary and secondary school for getting children awareness towards the difficult day to day reality their RD affected mates must face, and for promoting meaningful learning.

The main objective of this work in the long term, will be to standardize a protocol to carry out educational interventions in primary and secondary schools, especially in some of the schools attended in Navarre by RDAS, which end by the preparation of banks of RD Knowledge Models at the different schools, interacting until the creation of an immense network of knowledge.

The specific objectives are to offer a methodology in order:

- To facilitate meaningful learning through the use of metacognitive tools such as Concept Maps (CM) [20]

- $\quad$ To promote awareness and empathy by showing the complex reality of RDAS to their peers, as a tool for avoiding bullying.

\section{Materials and Methods}

The educational intervention, can start being implemented in Primary Education schools, in subjects such as "Natural Sciences", addressing the second content block of the Natural Sciences Curriculum (BON, September 2005) [25], titled, "The human body and health"; in the subject "Social and civic values", covering block 1 (The identity and dignity of the person), block 2 (Understanding and respect in international relations) and block 3 (Coexistence and social values); in the subject "Mathematics", covering the content block 2 (Numbers), block 3 (Measures) and block 5 (Statistic and probability); in the subject "Artistic Education", encompassing the blocks 5 (Interpretation or acting) and 6 (Listening); in the subject "Physical Education", including blocks 1 (Perceptive motor skills), 2 (Physical motor skills), 3 (Expressive artistic skills) and 4 (Physical ability and health).

The educational agents involved will be GERNA's families, teachers from the Primary Education schools interested in developing the project, teachers from the Public University of Navarre, and some students already graduated from the Degree in Primary Education, who will be the ones hired by GERNA [11] association to develop the project in the schools.

\subsection{Awareness}

Being one of the specific objectives of this work, a program has been designed:

Visit of GERNA's teachers (graduated students from the Degree in Primary Education).
- Activity 1: GERNA's teachers visit the school where one of the students is affected by a rare disease, and explain what RD are and how many people can suffer them in relation to the total population. This way, the students can study quantities, numbers, proportions and units of measure according to blocks 2, 3 and 5, from the subject Mathematics of the Primary Education Curriculum (BON, September 2005).

- Activity 2: Then, GERNA's teachers tell a tale "Ana Montaña" (in print), about one child suffering a RD and pose questions to children about how they would feel if they were in his shoes, how they would act... encouraging a debate or discussion among children, according to blocks 2 and 3 of the subject Social and Civic Values.

- Activity 3: Role playing. GERNA's teachers hand out different disability roles to each student so that everyone is limited to any of the activities proposed by the teachers. There will be blind students, deaf, with hip mobility problems, with speaking problems, with problems to breathe properly... In each activity, as for example, "you have to drink water from a glass of water", children will have to think if their new state allows them to do it or not. If they can't, they will have to tell the rest of the students why they are not able to perform that concrete activity and how they feel. Again in this activity, the blocks of contents 1, 2 and 3 of the subject Social and Civic Values are used, but also, the blocks of contents 5 and 6 from the subject Artistic Education, and the blocks 1, 2,3 and 4 of the subject Physical Education.

- Activity 4: GERNA's teachers will encourage the children according to the role they have played in activity 3 , to reflect on what people may need in their day to day or who they depend on to function throughout the day, as for instance, parents, friends, teacher, caregiver, nurse, physiotherapist. In this activity, the blocks of contents 1,2 and 3 of the subject Social and Civic values are the ones used.

\subsection{Facilitate Meaningful Learning through the Use of Metacognitive Tools Such as Concept Maps (CM)}

2.2.1. Development of Knowledge Models: For This Specific Goal, It Is Suggested the Creation of Knowledge Models (KM) Using Cmap Tools Software

- Activity 5: It is imperative students learn the basis of concept maps (CM). For that, we can start with the family tree (grandfather, grandmother, father, mother, brother, sister...), so that they become familiar with concepts, hierarchies and associations. In these simple CM, children can discuss about 
health and disease, tell if their families have or not a disease, if it is rare or not, and why.

- Activity 6: The RD affected child can tell about the characteristics of his or her disease (if it is appropriate or wants to do it), how he or she was diagnosed, which problems he or she has to face in a daily basis, so that a discussion about health and disease is generated. At this point, children will be working block 2 (The human body and health) of the subject Natural Sciences, and children can look for information on RD and therapeutic treatments in their tablets or in the computer and they put it all together and organize the information in a huge map on the blackboard, which will become the root map of the RD Knowledge Model.

\subsection{Creation of RD Knowledge Models Net (RDKMN)}

- Activity 7: Students play an active role and use the free software Cmap Tools [6] to create a Knowledge Model (KM). KMs are useful tools to create meaningful learning and avoid conceptual misconceptions $[6,19]$. Concept maps are dynamic creatures, susceptible of changes, as long as the students' cognitive structure changes, making new associations or incorporating new and more inclusive concepts. Working together designing a $\mathrm{KM}$, is a way of cooperative learning, compatible with a constructivist philosophy and the psicopedagogica theories of Novak [18], Ausubel [4] and Gowin [15].

We suggest the elaboration of a Knowledge Model $(\mathrm{KM})[2,6]$ in the context of a natural science class, addressing health and illnesses (Block 2 of the Primary Education Curriculum of Navarre) [25]. This KM is designed by all the students and it must contain a Root map, which in turn encompasses several subordinated maps for explaining the objectives of this work, and the future claim of performing an educational intervention as good practice example in primary and secondary education centers. This $\mathrm{KM}$ can explain some of the symptoms, difficulties of diagnostic, treatment possibilities, foundations and research groups of the specific RD the student has, so that his or her peers get to know them and become more empathetic with him or her, understand the difficulties he or she has in an ordinary day, helping the normalization of the $\mathrm{RD}$ in the educational context, and therefore, in the whole society. In this educational intervention, students learn to work in a cooperative way, feel more empathy towards affected students, learn the scientific method, and research and medical concepts and by means of the ICT, Cmap Tools, it can be possible to measure the change in their cognitive structure regarding their previous knowledge and the evolution of the generated maps.

The final goal after performing the 7 activities would be that each school will develop a CM referring to the rare disease of its student, and thus, a bank of $\mathrm{CM}$ of rare diseases with visibility in the schools of Navarre could be generated. This way, they could be more easily known in the whole society and it would be the beginning of a process of cultural normalization towards what entails being affected by a RD.

\section{Results}

\subsection{Vee Diagram or Gowin's Epistemological "V"}

Gowin's epistemological studies [15] and his concern about educational problems led him to invent the Vee diagram. This instructional resource incorporates 12 elements in the process of knowledge construction providing a much broader framework for more effective research reference, and it includes not only the steps of the scientific method, but also the specific knowledge of the concepts, principles, theories and philosophy guiding the research [15]. The Vee diagram [13] is a method which helps students and educators to analyze the structure and meaning of the knowledge they try to understand (metacognition) and allows the incorporation of new knowledge to the theoretical / conceptual structure the student already has, which is called meaningful learning [5]. According to Novak and Gowin[20], it is an heuristic device, used to help solve a problem or to understand a procedure. The shape of "V", is not an accident, but it was designed to house on the left side the conceptual / theoretical (thinking) part and on the right side, the methodological / practical (doing) part, both directed to refer to objects and events in the process of knowledge production. In this case, UPNA's teachers designed a Vee diagram to focus on the project's goals and which shows all the procedure (conceptual and methodological) to be carried out in schools attended by RDAS. 


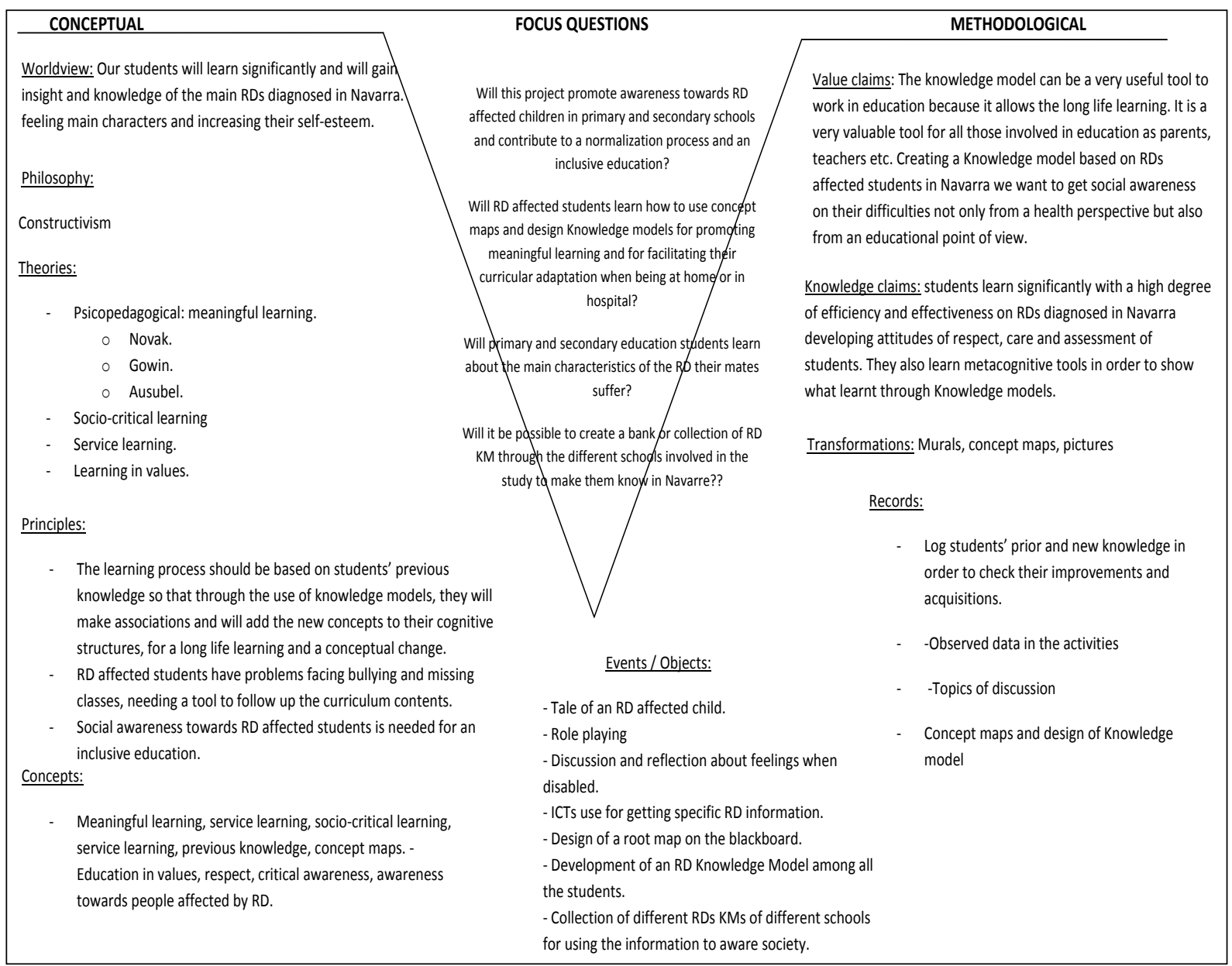

Figure 1. Vee diagram showing both sides, conceptual and methodological, and highlighting the focus questions which will guide the project

The V diagram (Figure 1) has been designed in order to answer the following focus questions which represent the objectives of this work:

- Will this project promote awareness towards RD affected children in primary and secondary schools and contribute to a normalization process and an inclusive education?

- Will RD affected students learn how to use concept maps and design Knowledge models for promoting meaningful learning and for facilitating their curricular adaptation when being at home or in hospital?

- Will primary and secondary education students learn about the main characteristics of the RD their mates suffer?

- Will it be possible to create a bank or collection of $\mathrm{RD} \mathrm{KM}$ through the different schools involved in the study to make them get known in Navarre?

Since the enactment of the 1989 Convention on the Rights of the Child (CRC), domestic legislation has been adapting to the principles contained in the Declaration. Although legislation and the legal system of each country might be different, 193 countries have been devoting special measures for their protection, at the legislative and constitutional rights. Within the Rights of the Child four key principles are highlighted:

(1) Non-discrimination: all children have the same rights.

(2) The interests of the child: any decision, law, or policy that may affect the child has to take into account what is best for the child.

(3) The right to life, survival and development: all children have the right to live and have a proper development.

(4) Participation: minors have a right to be consulted on situations that affect them and their views must be taken into account.

By means of this proposal we pretend to give voice to RDAS and try to make them have the same opportunities as any other children to be educated and to live their lives from a wider perspective. In order to fulfill the four key principles of the Convention of the Rights of the Child (CRC), the construction of RD based KM is provided as a tool available to all children, schools, teachers, and involved educational agents. KM will be built by students and they are examples of meaningful learning and 
knowledge creative cooperative construction $[13,5]$.

\subsection{Design of Knowledge Models (RDs) for Learning about RDs and Encouraging Social Awareness}

For the proposal of the educational intervention to be carried out in different primary education schools in Navarre, UPNA's teachers designed a general RD based KM to show the project's final goals and the educational process to follow.

The root map of the KM titled "Educational intervention for RD affected children" (Figure 2), was designed for promoting the learning of $\mathrm{RD}$, for showing the difficulties RDAS must confront throughout their whole life and for favoring social awareness.
However, the construction of the CM (some subordinated to others) is an iterative process in order to ensure thorough coverage of topic maps and faithful representation of expert knowledge [7, 8, 9]. Once constructed, required resources (photos, documents, videos, audio, Web pages, etc.) that best complement and explain the key concepts in CM must be selected.

This project will help in getting social awareness and meaningful and long life learning through the construction of Knowledge Models (KMs) and their design using CM.

The process of building a KM on "Rare Diseases in Navarre", therefore, involves the problems of RDAS in the health, social and educational field, as shown below in Figure 3.

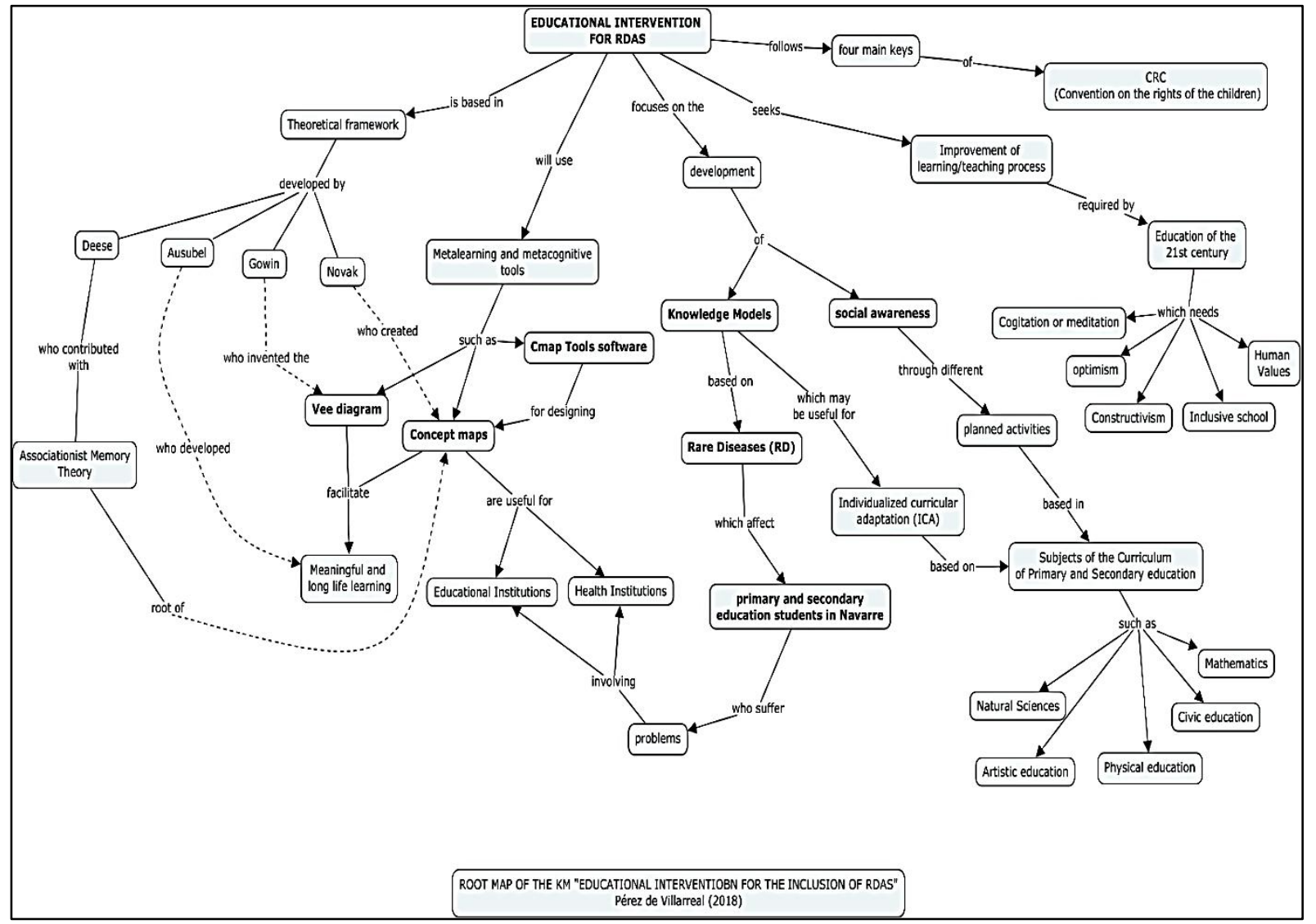

Figure 2. Root concept map of the KM entitled "Educational Intervention for RDSA", which contains other subordinated maps which conform the $\mathrm{KM}$ and which can be used as interface. 


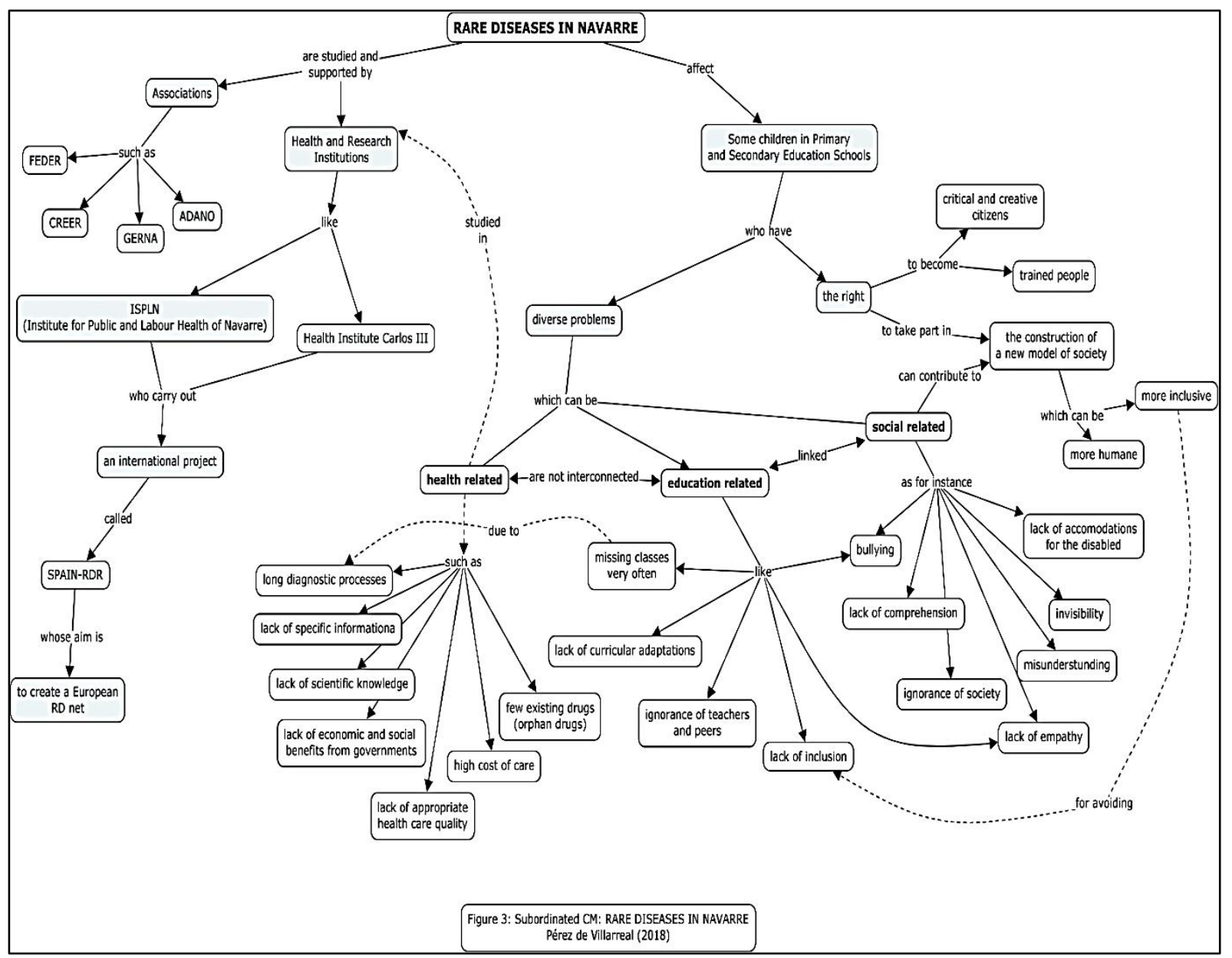

Figure 3. Subordinated concept map of the KM, titled "Rare Diseases in Navarre".

This CM shows the right RD affected children have to become educated people and critical and creative citizens (goals of the Education of the XXI century) and to take part in the construction of a new model of society which must be more humane and more inclusive. These children also face several problems which can be health, education and society related. Among the problems related to the health field, it is mentioned, the lack of specific and helpful information, the long diagnostic processes, the lack of scientific information, the high cost of care and therapies...In the education related problems, it is pointed out, the missing of classes (due to the diagnostic processes and the care and therapies), the lack of curricular adaptations, bullying, lack of inclusion...In the society related problems, it is noteworthy the invisibility, the lack of comprehension and empathy towards affected children and the ignorance.

In the next subordinated CM (Figure 4), the diagnosed Rare Diseases in Navarra which affect some children attending Primary education schools are shown. This CM can be useful for the final goal of the project, which consists in creating a bank or collection of KMs of the different Rare Diseases represented in Primary Schools of Navarre. 


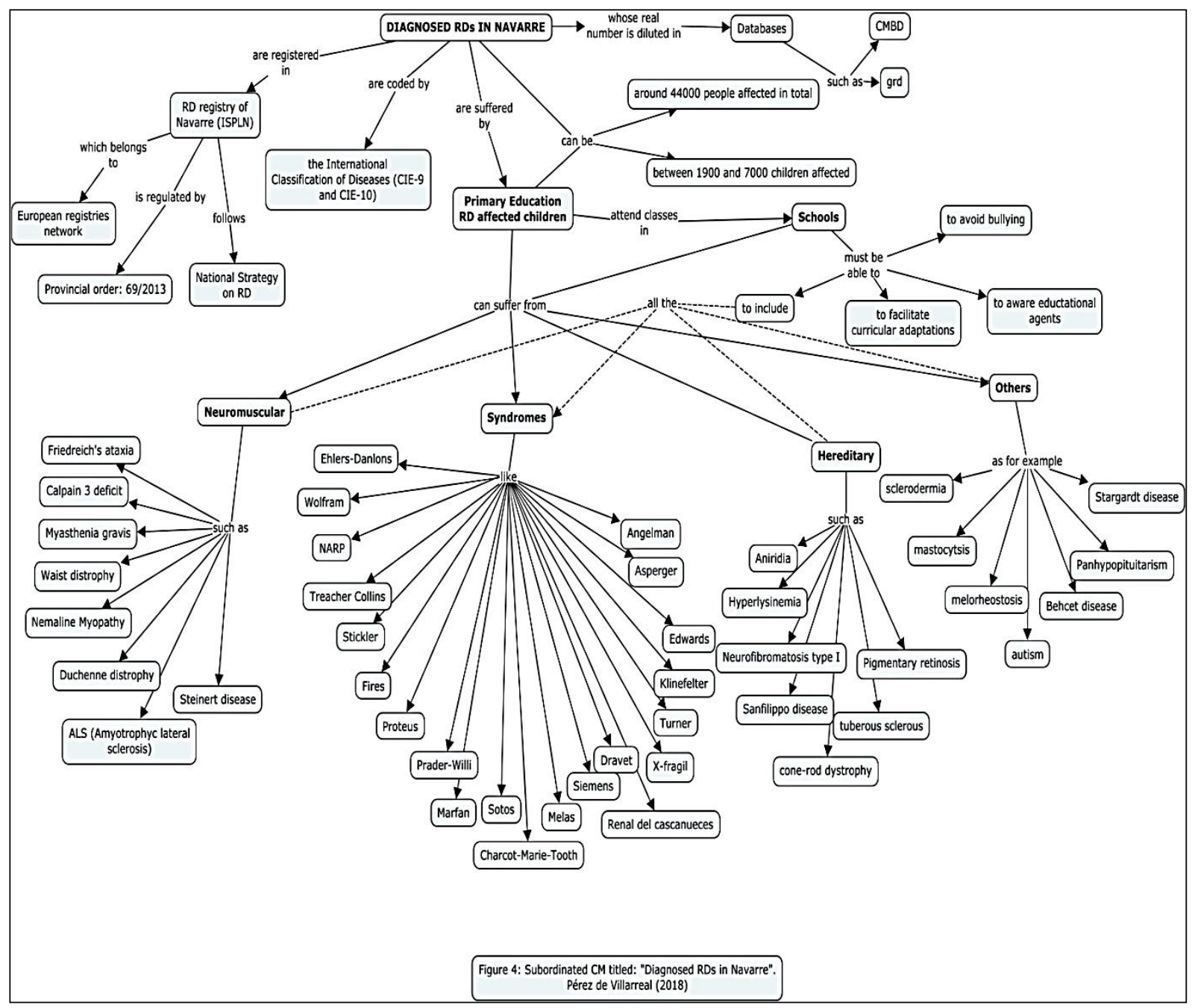

Figure 4. Subordinated concept map of the KM, titled "Diagnosed RDs in Navarre", which shows the different diagnosed RDs in Navarre and which can be represented in the different primary schools of Navarre, therefore providing information for developing KMs of the different RDs and contributing to create a bank of RDs KMs in Navarre.

To summarize, if clicking on the map from Figure 2, which represents the KM of the "Educational intervention for $\mathrm{RD}$ affected children" and contents the more general and inclusive concepts, we can use it as interface, being possible to navigate by clicking on the concept "Rare Diseases" This concept leads to the CM of Figure 3 "Rare Diseases in Navarre". If clicking on the concept "Some primary education children of Navarre", the CM of Figure 4 "Diagnosed RDs in Navarre" gets displayed. A number of details obtained by clicking the corresponding generic icons and graphics linked to concepts are also observed.
Through clicking on any of the RDs displayed, students can learn the main symptoms and characteristics of each disease. In each of the cases, in each school, they would learn about the disease affecting their peer but thanks to the bank of KMs they could also learn about the characteristics of other RDs affecting other Primary Education children in Navarre.

As an indication of protocol for any educational intervention with $\mathrm{RD}$ affected children, the following $\mathrm{CM}$ has been designed. 


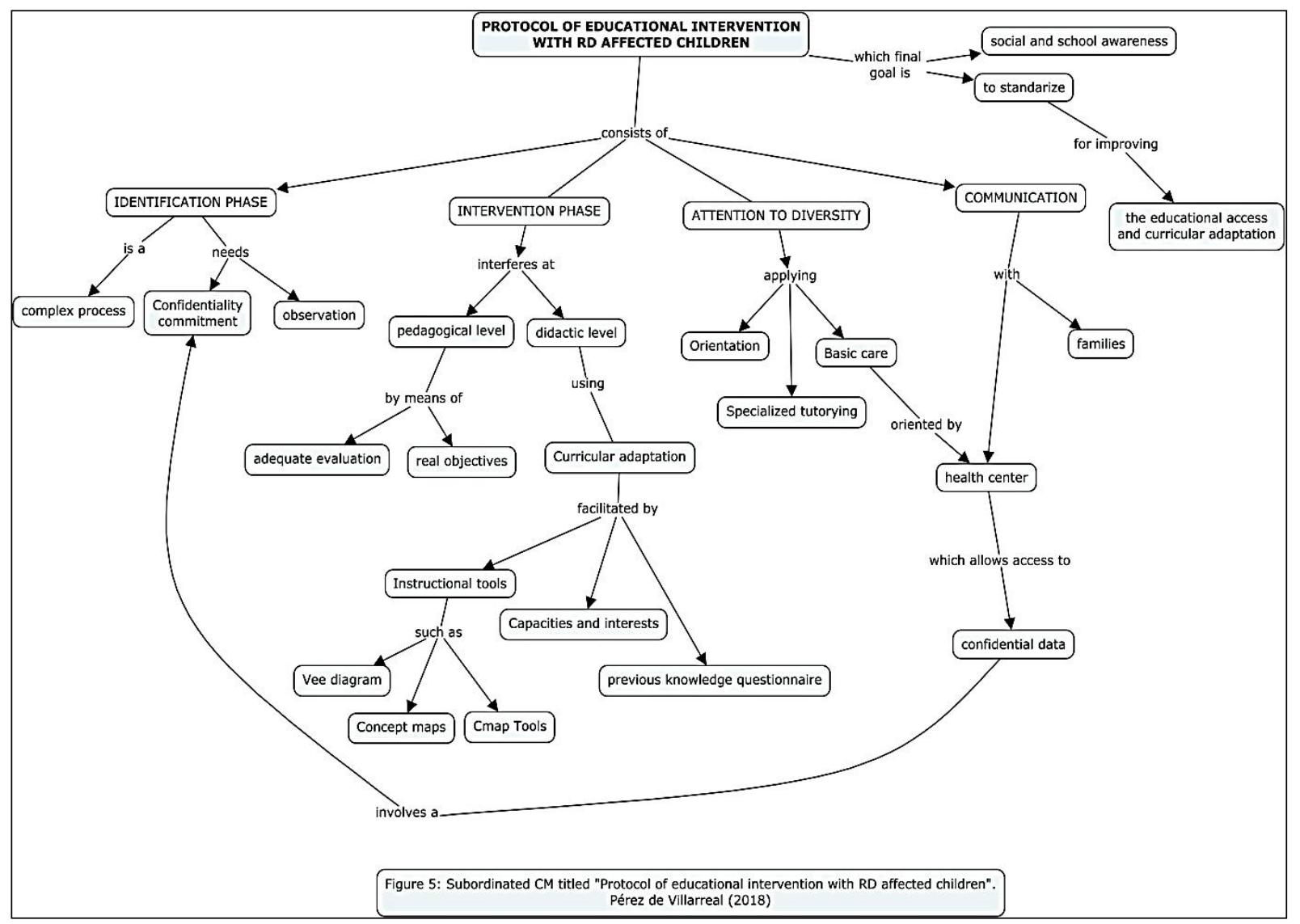

Figure 5. Concept map showing the protocol to follow for implementing the educational intervention in RDAS in order to standardize it in different schools in Navarre and to promote social awareness.

\section{Discussion}

UNESCO [26], states education is a fundamental human right, essential to exercise all other rights. It promotes freedom and personal autonomy generating significant benefits for one's development. However, millions of children and adults remain deprived of educational opportunities, in many cases because of poverty. However, there are also cases of education deprivation in developed countries. This is the case of disabled people, some of whom are RD affected, who miss classes frequently because of their health status. In this group, we would be talking about RDAS, who suffer the consequences of their health problems and hospital admissions and care therapies. However, in the most serious conditions, students cannot attend classes and therefore are in risk of getting out of the educational system. Only in the most fortunate cases but very infrequently, these students are subjected to individualized educational program (ACI) or curricular adaptations. It is up to governments to fulfill their obligations, both legal and policy reasons, relating to the provision of quality education for all and more effective implementation and monitoring of educational strategies. Through this article, we try to point out to the complicated world of RD and those who suffer them, with special emphasis on the primary education affected children. Through an immediate need identified by the association GERNA [11] in different Primary Education schools in Navarre (Spain), a proposal of educational intervention was designed, which can become a bigger project and which can help improve the educational and social situation of $\mathrm{RD}$ affected children in the long term, helping to standardize a protocol and to aware society and school about the real problems these students have to face in their daily basis.

The Vee diagram [15] designed by UPNA's teachers identified the key issues that led to the birth of this proposal and some of the focus questions have been answered through this work but others still need future work to be done. Nevertheless, the first and most important step is that RDAS should be able to be identified in infant or primary education schools, as the vast majority may need curricular adaptations (CA) in their future, due to the difficult diagnostic processes and the long treatment periods in which they must miss school. These students are also susceptible of suffering bullying, especially in the cases in which their physical appearance is different. In order to avoid or minimize these problems, it is necessary to bear in mind these children are also members of our society and will be part of our future, and 
we should provide them the tools to be included in an inclusive and egalitarian society; inclusion which must start in school and be reflected in society. In spite of the lifelong impact which many RDs entail and the beyond question complexity involved in many of these diseases, we have the moral duty of improving their education considering their right to be educated and take part of a changing society as human beings and develop themselves according to their possibilities, since there are some less serious conditions which are compatible with a better quality of life during childhood and youth. During this period and in cases in which students may attend classes (in person or virtually), we suggest the possibility of using ICTs (Technology of Information and Communication) such as the free software Cmap Tools (IHMC, Florida, USA). By using this tool we can facilitate their learning by creating knowledge models $[13,19]$, which may help them be more creative and feel more valuable for society, therefore increasing their self-esteem. Knowledge modelling is proposed as a methodology to be used in primary and secondary school for promoting meaningful learning, and also for encouraging their mates' awareness towards their difficult reality, fact that will spread later on in the whole society as it is a cultural and conceptual change which is being setting up. The intention is to implement instructional tools that could help RD affected students continue their education would also help the other students get to know about RDs and the reality affected people have to confront and accept and integrate RDAS as any other mate, normalizing their appearance and presence in class.

The main objective of this work in the long term, is to standardize a protocol to carry out educational interventions in primary and secondary schools, especially in some of the schools where RDAS study, and create banks of diagnosed Rare Diseases Knowledge Models which can be useful for other schools and other students in this or other countries. But particularly in this proposal, we show how to create KMs, based on information that the student must turn upon a previous assessment and transform it into substantive and useful knowledge into their cognitive structure. Each map contained in the KM, is derived from the foregoing, powering their own meanings. The KM is like a building which has been built based on meaningful learning and it is original, because although the information was there, reorganizing it and its consequent re-conceptualization has led to the development of an original model, open to any improvements, by some students able to add value to it with new information relevant to them and having an organized mind. CM helps identify, understand and organize the concepts we plan to teach and also help to specify the relationships (propositions) necessary for the understanding [13]. CM prepared by the student is an effective way of knowing what he/she already knows. As a key principle in education is to start considering what the learner already knows, to investigate is a very important task in any educational initial step [22]. The use of CmapTools and the building of their own knowledge provide students with resources to acquire significant learning, change their cognitive structure at the time it energizes their learning, and enable them to adapt to the rest of the class, despite the abstention of school associated with their disease [23]. The experience of connecting new information to existing knowledge in a meaningful way [13], causes positive feelings on students, and when they recognize the change in their own cognitive structure, the meaning of this experience changes in a powerful and lasting way.

Through the educational intervention, students will get to know the characteristics of the main RDs in Navarre, especially the one affecting their mate, and once they know the difficulties RDAS confront because of their health, empathy arises and the bullying shadow starts disappearing. Further research is needed in order to confirm the possibility of using KMs and Vee diagrams as ICA (Individual Curricular Adaptation), but evidence to support these value judgments are the results of other investigations $[2,5,22,23]$. The aim is that students achieve meaningful learning through the construction of $\mathrm{KMs}$, based in the particular case of a RD affected mate in class. This way, students affected by RDs may continue the lessons, and the rest of the students, learn about the reality of their colleagues being more empathic, always taking into account a confidentiality commitment, in which only what the RDAS and their families agree to tell is used. Every student, enabled or disabled has the right to learn in a meaningful way for the rest of his/her life (Convention of the rights of the child, 1989). Finally, it is remarkable the fact that education is a powerful tool that allows children and adults who are socially and economically marginalized to go out of poverty through their own efforts and participate fully in the community life.

\section{REFERENCES}

[1] ACNUR (1989). Convención sobre los derechos del niño. Disponible en:

www.arc-online.org/translations/spanish.html. Consulted 10th April 2014.

[2] Albisu S., San Martín, I., and González, F. (2006). Aplicación de los Mapas Conceptuales y de la V de Gowin en la Elaboración de Módulos Instruccionales en Alumnos de Magisterio. Proceedings of the Second International Conference on Concept Mapping. San José, Costa Rica, pp.48-50.

[3] Arostegui, I., Monzón, J., and Ozerinjauregui, N. (2017). Alumnado con enfermedades poco frecuentes y escuela inclusiva. Editorial Octaedro. 
[4] Ausubel, D. (2002). Adquisición y retención del conocimiento. Una perspectiva cognitiva. Ediciones Paidós. ISBN: 978-84-493-1234-2

[5] Ballester, A (2002): El aprendizaje significativo en la práctica. Cómo hacer el aprendizaje significativo en el aula. Libro digital gratuito en www.aprendizajesignificativo.com pág 192. Traducción al inglés (2011) Meaningful learning in practice. How to put meaningful learning in the classroom. En www.meaningfullearning.com. Traducción al catalán (2011). L’aprenentatge significatiu a la practica. Com fer l'aprenentatge significatiu a l'aula. www.aprenentatgesignificatiu.com. Extraído el 15 de Noviembre de 2011.

[6] Cañas, A. (2004). Cmap tools: A Knowledge Modeling and Sharing Environment. Proceedings of the First International Conference on Concept Mapping. Pamplona, Spain, pp $125-133$.

[7] Coffey, J., Hoffman, R., Cañas, A., and Ford, K (2002). A Concept Map-Based Knowledge modeling approach to Expert Knowledge Sharing. IKS. The IASTED International Conference on Information and Knowledge Sharing. November. Virgin Islands.

[8] Crandall, B., Klein, G., and Hoffman, R. (2006). Working Minds. A Practitioner's Guide to Cognitive Task Analysis. MIT Press: Cambridge, MA.

[9] Ericsson, K., Charness, N., Feltovich, P., and Hoffman, R. (2006). The Cambridge Handbook of Expertise and Expert Performance. Cambridge University Press: Cambridge, MA.

[10] EUCERD (2011). Report on the State of the Art of Rare Disease Activities in Europe. Part I: Overview of Rare Disease Activities in Europe.

[11] GERNA. Available at: $\mathrm{http}: / /$ enfermedadespocofrecuentes.org/quienes-somos

[12] González, D., and García, M (2008). Enfermedades raras en pediatría. An. Sist. Sanit. Navar 31 (Supl 2): 21-29.

[13] González, F. (2008). El mapa conceptual y el diagrama UVE. Recursos para la enseñanza superior en el siglo XXI. Editorial Narcea.

[14] González, F., Morón, C., and Novak, J. (2001). Errores conceptuales. Diagnosis, tratamiento y reflexiones. Pamplona: Ediciones Eunate.

[15] Gowin, D.B. (1981). Educating. Ithaca, NY: Cornell University Press.
[16] Institute of Statistics of Navarre. Available at https://www.navarra.es/home_es/Gobierno+de+Navarra/O rganigrama/Los + departamentos/Economia $+y+$ Hacienda/O rganigrama/Estructura+Organica/Instituto+Estadistica/

[17] Meichenbaum, D., and Biemiller, A. (1998). Nurturing Independent Learners. Helping Students take Charge of their Learning. Cambridge, Massachusetts. Brookline Books.

[18] Novak, J. (1998). The pursuit of a Dream: Education Can Be Improved. In J. Mintzes, Wandersee J. and Novak, J. Teaching Science for Understanding. A Human Constructivist View. San Diego: Academic Press. p.p. 3-28.

[19] Novak, J. and Cañas, A (2006): The Theory Underlying Concept Maps and How to Construct Them (Technical Report IHMC CMap Tools 2006-11). Florida Institute for Human and Machine Cognition.

[20] Novak, J., and Gowin, D.B. (1984): Learning how to learn. Cambridge University Press

[21] Palacio, R.J. (2012). La lección de August. Editorial Nube de Tinta

[22] Pérez de Villarreal, M., Cano, N. and González, F. (2015). Knowledge models as meaningful and long life learning alternative for Rare Disease affected students. American Journal of Educational Research, 3(1), pp100-108. DOI:10.12691/education-3-1-17

[23] Pérez de Villarreal, M. and González, F. (2014). Knowledge models as meaningful and long life learning alternative for rare disease affected students. Proceedings of the Sixth International Conference on Concept Mapping. Sao Paulo, Brasil, pp 646-650.

[24] Posner, G., Strike, K., Hewson, P., and Gertzog, W. (1982). Accomodation of a scientific conception: toward a theory of conceptual change. Science Education, 62 Vol.2, 211-227.

[25] Primary Education Curriculum of Navarre. BON número 174, de 5 de septiembre de 2014. Available at: https://www.navarra.es/NR/rdonlyres/B62A9CFB-C17B-4 61E-BD7D-BBEE005C2096/0/F1410295 EducacionPrim aria.pdf

[26] UNESCO ((United Nations Organization for Education, Science and Culture). Available at: https://es.unesco.org/themes/education

[27] Villar, L., and Alegre, O. (2004). Manual para la Excelencia en la Enseñanza Superior. Madrid: Mc Graw Hill. 